\title{
Effects of White Roman gosling quality on their growth parameters, intestinal villus morphology, blood biochemistry, and nonspecific pathological lesions
}

\author{
Min Jung Lin ${ }^{1,3}$, Shen Chang Chang ${ }^{2,3}$, Min Ting Lee ${ }^{3}$, Yong Tien Tien ${ }^{4}$, Jiunn Wang Liao ${ }^{4}$, \\ Tzu Tai Lee ${ }^{3,5^{*}}$
}

\footnotetext{
${ }^{1}$ Council of Agriculture, Livestock Research Institute, Changhua Animal Propagation Station, Taiwan.

${ }^{2}$ Council of Agriculture, Livestock Research Institute, Kaohsiung Animal Propagation Station, Taiwan.

${ }^{3}$ National Chung Hsing University, Department of Animal Science, Taiwan.

${ }^{4}$ National Chung Hsing University, Graduate Institute of Veterinary Pathobiology, Taichung, Taiwan.

${ }^{5}$ National Chung Hsing University, iEGG and Animal Biotechnology Center, Taichung, Taiwan.
}

\begin{abstract}
The purpose of this study was to investigate the effects of gosling quality on their growth parameters, intestinal villus morphology, blood biochemistry, and nonspecific pathological lesions from 0 to 4 weeks old. Seventy-two goslings were randomly distributed into 12 pens, with each pen containing three males and three females in a completely randomized design of two control variables, including healthy and weak goslings. Healthy goslings all shared the same characteristics, such as good features with no abnormalities and full absorption of yolk sac. Albeit lighter body weight $(<85 \mathrm{~g} / \mathrm{bird})$ and incomplete absorption of the yolk sac were found in the weak geese, no obvious disease was exhibited in them. Post mortem examination revealed that the incidence of nonspecific pathological lesions of the 4 week-old healthy and weak gosling groups were 25.0 and $50.0 \%$, respectively. Nonspecific pathological changes of 4 week-old goslings in the liver, ileum, lung, and heart were $16.7,12.5,8.3$, and $4.2 \%$, respectively. The healthy goslings also had higher total cholesterol, high-density lipoprotein, and low-density lipoprotein than weak goslings. Separately raising weak goslings from 0 to 4 weeks old could increase the survival rate and reduce economic losses of feeding.
\end{abstract}

Key Words: animal production, physiology, poultry

\section{Introduction}

The major breed of meat geese in Taiwan is the White Roman goose (97\% of the market). In Taiwan, according to statistics data from the Council of Agriculture, Executive Yuan (2012), the goose industry makes 2.29 billion NT dollars a year, involving 4.93 million geese slaughtered for meat, and goose number on farms at the end of the year was 1.86 million. A statistical report of the Taiwanese goose industry in 2013 stated that there were 8.8 million fertilized eggs and 6.5 million of hatching goslings; therefore, the hatchability of fertile eggs was $72.7 \%$ (Goose Association of the Republic of China, 2013).

The age of parent geese influences the weight of hatching eggs and of one-day-old goslings (Shanawany,

Received: February 16, 2017

Accepted: November 25, 2017

*Corresponding author: ttlee@dragon.nchu.edu.tw

Copyright (C) 2018 Sociedade Brasileira de Zootecnia. This is an Open Access article distributed under the terms of the Creative Commons Attribution License (http://creativecommons.org/licenses/by/4.0/), which permits unrestricted use, distribution, and reproduction in any medium, provided the original work is properly cited.
1987). Also, species will affect the characteristics of eggs. For instance, the Babat Grey Landes breeders produce heavier eggs and goslings than inexperienced breeders (Spiller et al., 2003). Egg weight have a positive relationship to the weight of newborns (Shanawany, 1984; Lin and Hsu, 1998; Saatci et al., 2005). Peebles et al. (2001) indicated that breeder age has a significant effect on chick body weight at incubation. Ramaphala and Mbajiorgu (2013) indicated that large-sized eggs produce chicks with higher hatch-weight than medium and small-sized eggs. Taking all of this into account, the size of fertilized eggs has been shown to be related to the age of breeders. Moreover, larger fertilized eggs typically produce heavier goslings. Petek and Dikmen (2006) indicated that pre-storage incubation and length of egg storage affect hatchability. Petek et al. (2010) showed that length of day-old chick could affect body weight from 1-35 days. So, higher-quality chicks at birth will have better growth performance.

Tona et al. (2003) indicated that there is a negative linear relationship between chick relative growth and egg weight and between relative growth and day-old chick weight. These authors indicated that estimation 
of chick quality included physical conditions such as activity, feathering, eyes, conformation of legs, aspect of navel area, and yolk absorption of day-old chicks. Chicks were examined macroscopically to identify the different characteristics that could be associated with good-, average-, or poor-quality chickens. Van de Ven et al. (2012) reported that the quality of chicks was evaluated based on five criteria: navel condition (black button and/or leaky navel); yolk sac (large size of the residual yolk sac); red hocks (red and/or swollen hocks); abnormal beak (red beak and/or nostrils contaminated with albumen); and low alertness.

Bednarczyk and Rosinski (1999) reported that White Italian geese and Kuban geese have a weak gosling birth rate of 6.6 to $11.5 \%$ of total goslings. Muhammad et al. (2009) found that the rate of culled chicks was 0.19 to $10.9 \%$ in hatcheries. Ulmer-Franco et al. (2010) reported that the rate of culled chicks at hatching was 0.3 to $3.2 \%$. These reports have demonstrated that, under normal conditions, more weak goslings are born than weak chicks. However, a higher rate of weak goslings may lead to a decrease of both product and profit. In a commercial geese farm, weak goslings may be isolated until they recover to normal status. Those weak goslings in serious conditions or those that have not fully absorbed the yolk sac are suggested for euthanasia.

According to Heier et al. (2002), the mortality rate in the first week was higher than the average weekly cumulative mortality during the growing period, and the main causes of mortality of 1-7 week-old broilers were syndrome, colibacillosis, yolk sac infection with omphalitis, and cecal coccidiosis (Buragohain and Kalita, 2010). In the present study, we tried to connect the relationship between gosling quality and growth characteristics, including some parameters such as biochemistry and prevalence of disease to provide more reference for gosling farming.

\section{Material and Methods}

Research on animals was conducted according to the institutional committee on animal use (LRICH IACUP 10409). The experiment was conducted in Changhua (located at $23^{\circ} 51^{\prime} \mathrm{N}$ and $120^{\circ} 33^{\prime} \mathrm{E}$ ), Taiwan.

A total of 520 White Roman breeder geese, including 120 males and 400 females at the 3rd parity, were moved to a controlled-environment breeding house before the laying period. The gander to goose ratio was 1:3.33 at the initial stage. The controlled-environmental breeding house was $12.0 \times 38.0 \mathrm{~m}$ with a total area of $456 \mathrm{~m}^{2}$ and $1.22 \mathrm{~m}^{2}$ per goose. Ten feeding tanks, 20 water dispensers, and one pond measuring $38 \times 0.8 \times 0.3 \mathrm{~m}$, were provided in each house. The laying diets contained $18 \%$ crude protein (CP) and 2,650 kcal metabolizable (ME)/kg. White Roman goslings were hatched on March 7th, 2013.

Hatching eggs were kept at $18{ }^{\circ} \mathrm{C}$, and all the eggs collected in two weeks were hatched at the same time. Seventeen production clutches of fertilized eggs adding up to 24,243 eggs were tested for fertility and hatchability. The eggs were then placed into an automatic incubator (Tonz Nan Incubators Manufactured Co. Ltd., Taiwan) set at $37.7{ }^{\circ} \mathrm{C}$ for days $0-14$, at $37.5{ }^{\circ} \mathrm{C}$ for days $15-28$, and at $37.2{ }^{\circ} \mathrm{C}$ during hatching. Fertilized eggs were judged by naked-eye observation with beam of light in a candler in a dark room on 7th day after hatching. Hatchability was defined as the percentage of goslings hatched over the number of fertile eggs incubated. The percentage of fertility was measured as: (Total eggs - Non-fertilized eggs) $\div$ Total eggs $\times 100 \%$. Percentage of weak goslings was measured as: Number of weak goslings $\div$ Total goslings $\times 100 \%$.

During 0-4 weeks, 72 goslings were assigned to two treatments, healthy and weak gosling groups, regarding their health status, and each treatment included six pens, each containing three males and three females. Healthy goslings all shared the same characteristics, such as good features with no abnormalities and full absorption of yolk sac. Albeit lighter body weight ( $<85 \mathrm{~g} /$ bird) and incomplete absorption of the yolk sac were found in the weak geese, no obvious disease was exhibited in them. Hatching goslings were identified as of two types: healthy and weak goslings (Figure 1). The pen of the nursery house measured $2.4 \times 1.9 \mathrm{~m}$ $\left(4.56 \mathrm{~m}^{2}\right)$ with 1.35 goslings $/ \mathrm{m}^{2}$. It contained a wire floor, one tank, and one water dispenser. Basic feed was provided during the experiment $(20 \% \mathrm{CP} ; 2,900 \mathrm{kcal} / \mathrm{kg} \mathrm{ME})$.

Goslings were weighed at hatching, at 2 weeks old, and at 4 weeks old. Also, feed of each column was weighed to calculate the feed intake. The goslings were randomly selected, and blood samples were obtained by wing venipuncture before each goose was killed by exsanguination. The blood samples were centrifuged at $3000 \times g$ for $30 \mathrm{~min}$ at $4{ }^{\circ} \mathrm{C}$; samples were then stored at $-20{ }^{\circ} \mathrm{C}$ until analysis. Serum biochemical parameters analyses were performed by an Automatic Biochemical Analyzer (Hitachi, 7150 auto-analyzer, Tokyo, Japan). The goslings were sacrificed by cervical dislocation. Heart, kidneys, liver, lung, spleen, intestine, and testes or ovaries were collected and fixed in $10 \%$ neutral buffered formalin for pathologic examination. Tissues were further processed, embedded in paraffin, cut in $2 \mu \mathrm{m}$ size by microtone (Leica RM 2145, Nussloch, Germany), stained with hematoxylin 
and eosin staining, and evaluated under light microscope (BX-51, Olympus, Tokyo, Japan) for histopathological evaluation. Severity of lesions was graded according to the criteria described by Shackelford et al. (2002). Degree of lesions was graded from 1 to 5 depending on severity: $1=\operatorname{minimal}(<1 \%), 2=\operatorname{slight}(1-25 \%), 3=$ moderate $(26-$ $50 \%), 4=$ moderate/severe $(51-75 \%)$, and $5=$ severe $/$ high (76-100\%). Incidence rate was examined as numbers of affected geese/total number of geese.

A total of 24 four-week-old goslings (12 males and 12 females) from each group (one male and one female; two geese per pen) were randomly selected and sacrificed at the end of the experimental period. Goslings were weighed and then sent to electrocution and exsanguinated by the carotid artery. Abdominal fat and organs including heart, gizzard,

A - Healthy gosling

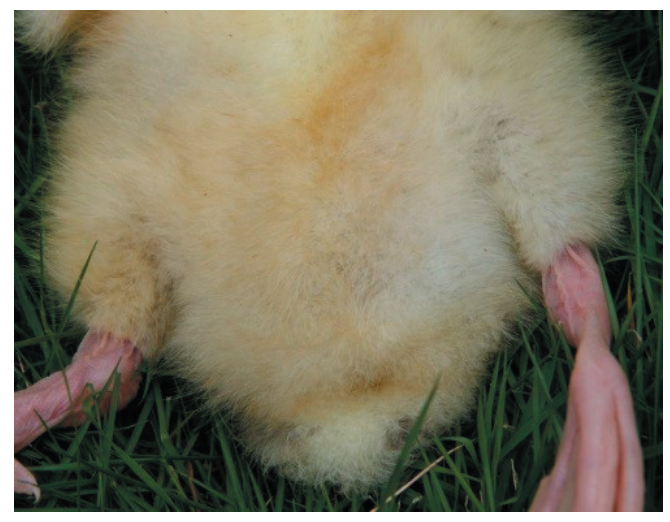

B - Weak gosling (incomplete absorption of the yolk sac)

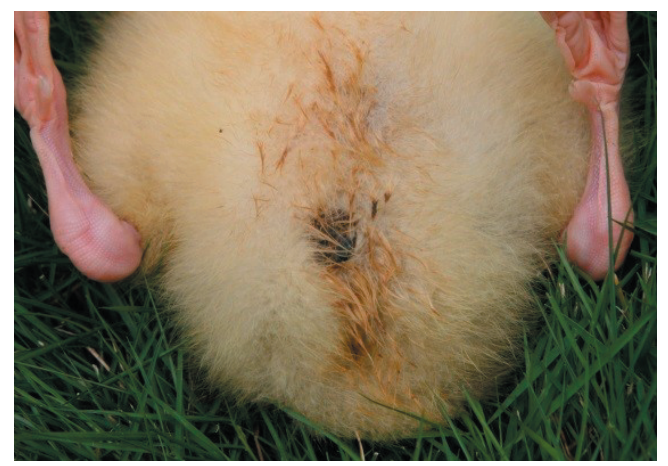

Healthy type of gosling (A); weak gosling with infirmity and puny and hatching weight smaller than $85 \mathrm{~g}$ or incomplete absorption of the yolk sac (B).

Figure 1 - The appearances of healthy and weak hatching White Roman goslings. liver, spleen, duodenum, ileum, and jejunum were weighed, as well as the carcass without these organs. The jejunum was identified from the duodenum to Meckel's diverticulum and the ileum was identified from Meckel's diverticulum to the ileocecal. Jejunum and ileum were fixed in $10 \%$ buffered formalin and three cross-sections were taken in the middle of the intestine. The sections of intestines were photographed in low-light and then calculated by the image Pro plus ${ }^{\circledR}$ (Image Pro-Plus, CA, USA).

Villi length, villi width, and crypt depth were determined by taking the average value of ten samples (Samanya and Yamauchi, 2002; Morales-López et al., 2009). Average villi area was determined as average villi length multiplied by average villi width (villus height $\times$ villus width $=$ area). Villus depth:crypt depth ratio (VD:CD) was determined as average villi depth divided by crypt depth (villus $\frac{\text { height }}{\text { crypt }}$ depth $=\frac{\mathrm{VD}}{\mathrm{CD}}$ ratio). All gross pathological lesions were recorded and severity of lesions was graded according to the methods described by Shackelford et al. (2002).

The data collected were statistically analyzed using the general linear models procedure (GLM) of SAS software (Statistical Analysis System, version 9.01), following a random arrangement. The mathematic model used was:

$$
\mathrm{Y}_{i j}=\mu+\mathrm{T}_{i}+\varepsilon_{i j} \text {, }
$$

in which $\mathrm{Y}_{i j}=$ observed response of the bird in the pen; $\mu=$ overall mean; $\mathrm{T}_{i}=$ fixed effect of gosling quality treatment; and $\varepsilon_{i j}=$ residual error when the pen was regarded as an experimental unit, $\varepsilon_{i j} \sim N\left(0, \sigma_{\varepsilon}^{2}\right)$. The mean values between two gosling quality treatments were compared using the LSMEANS with the significant level at $\mathrm{P}<0.05$.

\section{Results}

Results showed that White Roman geese had an average $77.7 \%$ fertility (Table 1 ). With the $84.1 \%$ hatchability, there were $5.16 \%$ weak goslings. The low percentage of weak goslings may be attributed to the 3 rd parity. Moreover, the total 15,839 goslings were hatched in an incubator and the total egg of hatchability was $65.3 \%$.

The weight at birth had a strong relationship with the physical condition of goslings ( 0.10 vs $0.09 \mathrm{~kg}$; $\mathrm{P}<0.05)$ (Table 2). The body weights were not different between different treatment groups at two and four weeks, indicating

Table 1 - Effect of gosling quality on hatching of White Roman breeder geese

\begin{tabular}{|c|c|c|c|c|c|c|c|c|}
\hline \multirow{2}{*}{$\begin{array}{l}\text { Egg number } \\
\text { (egg) }\end{array}$} & \multirow{2}{*}{$\begin{array}{c}\text { Number of fertilized eggs } \\
\text { (egg) }\end{array}$} & \multirow{2}{*}{$\begin{array}{l}\text { Fertility } \\
(\%)\end{array}$} & \multirow{2}{*}{$\begin{array}{l}\text { Hatchability } \\
\qquad(\%)\end{array}$} & \multirow{2}{*}{$\begin{array}{l}\text { Egg weight } \\
(\mathrm{g})\end{array}$} & \multirow{2}{*}{$\begin{array}{c}\text { Gosling weight } \\
\text { (g) }\end{array}$} & \multicolumn{2}{|c|}{ Type of gosling (bird) } & \multirow{2}{*}{ W $(\%)$} \\
\hline & & & & & & $\mathrm{H}$ & W & \\
\hline 24,243 & 18,834 & 77.7 & 84.1 & 181 & 108 & 15,022 & 817 & 5.16 \\
\hline
\end{tabular}

H - healthy gosling; W - weak gosling. 
that the physical condition at birth did not affect the continued growth performance of goslings. In other words, even though the weak goslings were lighter at birth, the rates of weight gain were similar to the healthy birds. Thus, the weak goslings are able to obtain normal weight after receiving more attention and care, and the cost of waste can be avoided.

Weak goslings had a higher mortality rate at the 2nd week of the raising period and had higher mortality rates from birth to four weeks than healthy goslings (Figure 2).

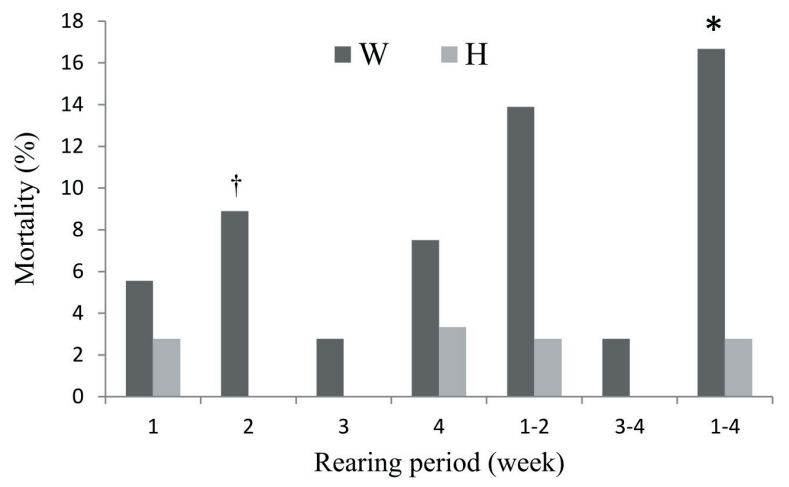

$\mathrm{H}$ - healthy gosling; W - weak gosling. $+\mathrm{P}<0.10$.

$* \mathrm{P}<0.05$.

Figure 2 - Effect of gosling quality on mortality during rearing period of White Roman geese.

Table 2 - Effect of gosling quality on growth performances of White Roman geese ${ }^{1}$

\begin{tabular}{lccc}
\hline \multirow{2}{*}{ Item } & \multicolumn{2}{c}{ Type of gosling } & \\
\cline { 2 - 3 } & Healthy & Weak & \\
\hline Body weight (g/goose) & & \\
$\quad$ Birth & $104 \mathrm{a}$ & $87.7 \mathrm{~b}$ & 24.6 \\
2 wk & 726 & 715 & 26.5 \\
4 wk & 1700 & 1760 & 57.2 \\
Body weight gain (g/bird) & & & \\
Birth - 2 wk & 622 & 626 & 26.8 \\
3 - 4 wk & 965 & 1056 & 51.4 \\
Birth - 4 wk & 1586 & 1675 & 57.9 \\
Feed intake (g feed/bird) & & & \\
Birth - 2 wk & 1103 & 957 & 69.0 \\
3 - 4 wk & 2204 & 2021 & 73.4 \\
Birth - 4 wk & 3307 & 2978 & 109 \\
Feed conversion ratio (feed/gain) & & & \\
Birth - 2 wk & 1.78 & 1.52 & 0.12 \\
3 - 4 wk & 2.29 & 1.97 & 0.15 \\
Birth - 4 wk & 2.09 & 1.80 & 0.11 \\
Mortality (\%) & & & \\
Birth - 2 wk & 2.78 & 13.9 & 0.041 \\
3 - 4 wk & 0 & 2.78 & 0.020 \\
Birth - 4 wk & $2.78 \mathrm{~b}$ & $16.7 \mathrm{a}$ & 0.036 \\
\hline
\end{tabular}

SEM - standard error of means.

${ }^{1}$ Results are given as the means of 12 pens containing six geese each.

$\mathrm{a}, \mathrm{b}$ - Means in the same row with different letters differ significantly $(\mathrm{P}<0.05)$.
The average weekly mortality of weak and healthy goslings was 6.18 and $1.53 \%$, respectively. Although the statistics of mortality showed no significant difference, mortality of weak goslings was higher in the 2nd week of the raising period, and the cumulative mortality from hatching to the 4th week of the raising period was higher than that of healthy birds.

The incidence of pathological lesions of healthy and weak goslings was $25.0(3 / 12)$ and $50.0 \%(6 / 12)$, respectively (Table 3 ). The major lesions were found in the liver, lung, and ileum. The survival rate of healthy goslings at four weeks old was $97.2 \%$, higher than that of weak goslings $(83.3 \%)$. The results demonstrate that the quality of goslings could affect the survival rate of geese.

Four-week-old healthy geese had lower triglycerides (TG) than weak goslings (148 vs $217 \mathrm{mg} / \mathrm{dL}$; $(\mathrm{P}<0.10)$. Healthy goslings also had higher total colesterol (TC; 204 vs $160 \mathrm{mg} / \mathrm{dL}$; $\mathrm{P}<0.01$ ), high-density lipoprotein (HDL; 107 vs $74.4 \mathrm{mg} / \mathrm{dL} ; \mathrm{P}<0.01$ ), and low-density lipoprotein (LDL; 71.0 vs $48.8 \mathrm{mg} / \mathrm{dL} ; \mathrm{P}<0.01$ ) than weak goslings (Table 4). In this study, the average villus height of weak goslings was higher than that of healthy goslings $(1,050$ vs $979 \mu \mathrm{m} ; \mathrm{P}<0.10$ ) (Table 5), but no difference was found between different treatment groups indicating that the quality of goslings does not affect the condition of the intestines. In this study, the condition of goslings affected the biochemistry values of serum, such as TC, HDL, LDL, and TG. This implies that gosling quality might influence blood biochemical parameters, which may further affect survival rates of gosling.

Table 3 - Effect of gosling quality on the incidence of nonspecific pathological lesions in White Roman geese

\begin{tabular}{lcc}
\hline \multirow{2}{*}{ Item } & \multicolumn{2}{c}{ Type of gosling } \\
\cline { 2 - 3 } & $3 / 12$ & Weak \\
\hline Incidence of nonspecific pathological lesions & $6 / 12$ \\
Severity of nonspecific pathological lesions of tissue & \\
Heart & $1(1)$ & - \\
Liver & $1(1), 2(1)$ & $1(1), 2(1)$ \\
Lung & - & $2(2)$ \\
Ileum & - & $1(2), 2(1)$ \\
Jejunum & $\mathrm{NS}$ & $\mathrm{NS}$ \\
Kidney & $\mathrm{NS}$ & $\mathrm{NS}$ \\
\hline
\end{tabular}

NS - no significant lesion.

${ }^{1}$ Results are given as the means of 12 pens containing six geese each.

${ }^{2}$ The degree of lesions was graded from 1 to 5 depending on severity: $1=$ minimal $(<1 \%) ; 2=$ slight $(1-25 \%) ; 3=$ moderate $(26-50 \%) ; 4=$ moderate/severe $(51-75 \%)$ $5=$ severe/high $(76-100 \%)$.

Heart: infiltration, mononuclear cells, focal, minimal; liver: infiltration, glycogen, diffuse, slight infiltration, mononuclear cells, focal, slight; lung: inflammation, bronchiole, focal, minimal to slight, proliferation, lymph node, focal, slight to moderate; ileum: necrosis, crypt, focal, minimal to slight. 
Table 4 - Effect of gosling quality on blood biochemical parameters in four-week-old White Roman geese ${ }^{1}$

\begin{tabular}{|c|c|c|c|}
\hline \multirow{2}{*}{ Item } & \multicolumn{2}{|c|}{ Type of gosling } & \multirow{2}{*}{ SEM } \\
\hline & Healthy & Weak & \\
\hline WBC $\left(10^{3} / \mu \mathrm{L}\right)$ & 261 & 277 & 12.7 \\
\hline $\operatorname{RBC}\left(10^{6} / \mu \mathrm{L}\right)$ & 1.66 & 1.51 & 0.08 \\
\hline $\mathrm{HB}(\mathrm{g} / \mathrm{dL})$ & 9.08 & 8.57 & 0.39 \\
\hline HT (\%) & 27.9 & 25.8 & 1.25 \\
\hline MCV (fL) & 169 & 171 & 3.86 \\
\hline $\mathrm{MCH}$ (pg) & 55.0 & 57.1 & 1.32 \\
\hline $\operatorname{MCHC}(\mathrm{g} / \mathrm{dL})$ & 32.5 & 33.5 & 3.17 \\
\hline $\operatorname{PLT}\left(10^{3} / \mu \mathrm{L}\right)$ & 26.2 & 17.4 & 6.14 \\
\hline GLU (mg/dL) & 81.3 & 79.2 & 1.61 \\
\hline BUN (mg/dL) & 6.50 & 7.25 & 0.34 \\
\hline CREA (mg/dL) & 0.18 & 0.20 & 0.02 \\
\hline $\mathrm{UA}(\mathrm{mg} / \mathrm{dL})$ & 2.62 & 3.40 & 0.36 \\
\hline GOT (U/L) & 49.9 & 59.9 & 9.80 \\
\hline GPT (U/L) & 15.8 & 20.3 & 1.95 \\
\hline $\mathrm{TP}(\mathrm{g} / \mathrm{dL})$ & 3.57 & 3.67 & 0.13 \\
\hline $\operatorname{ALB}(\mathrm{g} / \mathrm{dL})$ & 1.80 & 1.84 & 0.06 \\
\hline $\operatorname{GLO}(\mathrm{g} / \mathrm{dL})$ & 1.77 & 1.83 & 0.07 \\
\hline $\mathrm{A} / \mathrm{G}$ & 1.02 & 1.02 & 0.02 \\
\hline $\mathrm{TG}(\mathrm{mg} / \mathrm{dL})$ & $148 y$ & $217 x$ & 27.5 \\
\hline $\mathrm{TC}(\mathrm{mg} / \mathrm{dL})$ & $204 a$ & $160 \mathrm{~b}$ & 9.53 \\
\hline $\mathrm{HDL}(\mathrm{mg} / \mathrm{dL})$ & $107 \mathrm{a}$ & $74.4 \mathrm{~b}$ & 7.35 \\
\hline $\mathrm{LDL}(\mathrm{mg} / \mathrm{dL})$ & $71.0 \mathrm{a}$ & $48.8 \mathrm{~b}$ & 5.32 \\
\hline
\end{tabular}

WBC - white blood cell; RBC - red blood cell; HB - hemoglobin; HT - hematocrit; MCV - HT/RBC; MCH - HB/RBC; MCHC - HB/HT; PLT - platelet; GLU - glucose; BUN - blood urea nitrogen; CREA - creatinine; UA - uric acid; GOT - glutamyl oxaloacetic transaminase; GPT - glutamyl pyrubic transaminase; TP - total protein; ALB - albumin; GLO - globulin; A/G - albumin/globulin; TG - triglycerides; TC - total cholesterol; HDL - high density lipoprotein; LDL - low density lipoprotein.

${ }^{1}$ Results are given as the means of 12 pens containing six geese each.

$\mathrm{a}, \mathrm{b}$ - Means in the same row with different letters differ significantly $(\mathrm{P}<0.05)$ $\mathrm{x}, \mathrm{y}-$ Means within the same row with different letters tend to differ $(\mathrm{P}<0.10)$. SEM - standard error of means.

Table 5 - Effect of gosling quality on the characteristics of intestinal villus in four-week-old White Roman geese

\begin{tabular}{|c|c|c|c|}
\hline \multirow{2}{*}{ Item } & \multicolumn{2}{|c|}{ Type of gosling } & \multirow{2}{*}{ SEM } \\
\hline & Healthy & Weak & \\
\hline \multicolumn{4}{|c|}{ Villus height $(\mu \mathrm{m})$} \\
\hline Jejunum & $979 x$ & $1050 \mathrm{y}$ & 28.0 \\
\hline Ileum & 1085 & 1054 & 49.6 \\
\hline \multicolumn{4}{|c|}{ Villus width $(\mu \mathrm{m})$} \\
\hline Jejunum & 163 & 162 & 6.05 \\
\hline Ileum & 159 & 180 & 10.4 \\
\hline \multicolumn{4}{|c|}{ Crypt depth $(\mu \mathrm{m})$} \\
\hline Jejunum & 245 & 246 & 12.1 \\
\hline Ileum & 263 & 271 & 13.8 \\
\hline \multicolumn{4}{|c|}{ Villus area $\left(\times 10^{3} \mu \mathrm{m}^{2}\right)$} \\
\hline Jejunum & 160 & 170 & 7.53 \\
\hline Ileum & 172 & 190 & 14.1 \\
\hline \multicolumn{4}{|c|}{ Villi height:crypt depth ratio } \\
\hline Jejunum & 3.99 & 4.27 & 0.20 \\
\hline Ileum & 4.13 & 3.89 & 0.27 \\
\hline
\end{tabular}

SEM - standard error of means;

$\mathrm{x}, \mathrm{y}-$ Means within the same row with different letters tend to differ $(\mathrm{P}<0.10)$.

\section{Discussion}

Egg weight was affected by age (Tufft and Jensen, 1991; Bednarczyk and Rosinski, 1999; Spiller et al., 2003;
Dudusola, 2013), nutrition (Pérez-Bonilla et al., 2012; Mousavi et al., 2013), and lighting (Alabi et al., 2012). Saatci et al. (2005) found that a significant positive correlation was found between egg weight and hatching weight of goslings. It was a regression coefficient between egg and hatching weight $\left(\mathrm{Y}=20.0318+0.512591 \mathrm{X} ; \mathrm{r}^{2}=0.51\right)$. Puchajda et al. (1988) indicated that relation of egg weight with hatching weight of goslings was 0.64 . The regression of hatching weight on egg weight was 0.74 . Shanawany (1984) indicated that hatching weight is highly correlated with egg size. Lin and Hsu (1998) indicated that lighter eggs hatched lighter goslings and lighter goslings had a lower survival rate. Another study showed that weak White Italian and Kuban goslings were 6.6 to $11.5 \%$, respectively (Bednarczyk and Rosinski, 1999). In this study, the mean egg weight was $181 \mathrm{~g}$ and mean gosling weight was $108 \mathrm{~g}$ (Table 1). A high rate of weak goslings may have an economic impact on a farm. In this study, goose eggs lighter than $120 \mathrm{~g}$ should be considered substandard and disposed of before hatching to increase the quality of newborns.

Lin and Hsu (1998) indicated that lighter native chickens at birth would also be lighter in six to 15 weeks. Studies have also indicated that lighter eggs of Koekoek chickens would lead to lighter chicks, and this condition would continue until seven weeks (Egbeyale et al., 2011; Alabi et al., 2012). In this study, the results did not match previous studies. This may be due to the fact that the weights of chicken eggs have a wider range ( 110 to $230 \mathrm{~g}$ ) than goose eggs. The wide range of egg weights would lead to a wide range of chick weights. Lighter chicks would lead to less feed intake. However, geese were totally the opposite. Lighter goslings at birth had similar feed intake as healthy ones, so the weight of weak goslings increased very fast. Thus, until four weeks, there was no difference between healthy and weak goslings.

Heier et al. (2002) found that the mortality rate during the first week was $1.54 \%$, and the average weekly cumulative mortality was $0.48 \%$ during the growing period. Chou et al. (2004) showed that broilers raised indoors with open-curtain ventilation had the lowest mean first week cumulative mortality, $1.30 \%$, relative to those raised indoors with negative pressure ventilation $(1.42 \%)$ and water-cooled ventilation (1.37\%). Weak goslings had higher mortality rates during the growing period. Higher mortality rates among weak goslings during the growing period were also found in this study. This phenomenon might be attributed to underweight goslings, incomplete absorption of the yolk sac, or delayed growth of weak goslings. Buragohain and Kalita (2010) indicated that the main causes of mortality in 1-7 week-old broilers are 
ascites syndrome (34.3\%), colibacillosis (19.23\%), yolk sac infection with omphalitis (12.18\%), and cecal coccidiosis $(8.33 \%)$. These findings demonstrate that weak goslings experience a higher incidence of pathological lesions, which might lead to higher mortality rates. Therefore, it is suggested that weak goslings be separated from flocks to increase their chances of survival.

Han et al. (1993) indicated that total cholesterol content in laying hens that received diet supplemented with cholesterol, soybean oil, and fish oil was higher than those of control groups. Naber (1983) indicated that liver cholesterol biosynthesis is affected by diet. Luquetti et al. (2004) indicated that red blood cell numbers, hematocrit, mean cell volume, hemoglobin, and blood viscosity of neonatal chicks are not affected by age in broiler breeder. Musa et al. (2007) reported that total cholesterol and HDL in serum differ among breeds. Then, male chickens had a higher serum of total cholesterol and LDL than those of the female group. In this study, healthy goslings also had higher TC, HDL, and LDL than weak goslings (Table 4).

\section{Conclusions}

Healthy goslings are heavier when hatched and fewer non-specific pathological lesions were found. Also, healthy goslings have higher survival rate. Weak goslings exhibit significant lighter body weight and higher mortality ratio at hatchling as comparing with the corresponding healthy group. Moreover, higher incidence of pathological lesions is also found in weak goslings than the healthy counterparts. During 0-4 weeks, weak goslings have a general higher mortality rate. Accordingly, we suggested that while the weak goslings were raised separately during 0-4 weeks, their survival rate could be improved with good care.

\section{Acknowledgments}

This work was financially supported by the Changhua Animal Propagation Station, COA-LRI, and the iEGG and Animal Biotechnology Center of The Feature Areas Research Center Program within the framework of the Higher Education Sprout Project by the Ministry of Education (MOE) in Taiwan.

\section{References}

Alabi, O. J.; Ng'ambi, J. W.; Norris, D. and Mabelebele, M. 2012. Effect of egg weight on hatchability and sebsequent performance of potchefstroom koekoek chicks. Asian Journal of Animal and Veterinary Advances 7:718-725.

Bednarczyk, M. and Rosinski, A. 1999. Comparison of egg hatchability and in vitro survival of goose embryos of various origins. Poultry Science 78:579-585.

Buragohain, R. and Kalita, G. 2010. Assessment of mortality pattern of broiler under intensives system of management in Mizoram. Tamil Nadu Veterinary and Animal Sciences 6:239-241.

Chou, C. C.; Jiang, D. D. and Hung, Y. P. 2004. Risk factors for cumulative mortality in broiler chicken flocks in the first week of life in Taiwan. British Poultry Science 45:573-577.

Council of Agriculture, Executive Yuan. 2012. Livestock production. In: Yearly report of Taiwan's agriculture. p.123-125.

Dudusola, I. O. 2013. The effect of parental age and egg weight on fertility, hatchability and day-old chick weight of Japanese quail (Cortunix cortunix japonica). Standard Research Journal of Agricultural Sciences 1:13-16.

Egbeyale, L. T.; Abiola, S. S.; Sogunle, O. M. and Ozoje, M. O. 2011 Effect of egg size and strain on growth performance of cockerel. Agriculture \& Biology Journal of North America 2:1445-1453.

Goose Association of the Republic of China. 2013. Yearly report of hatching in goose egg. Available at: <http://www.goosetw.com/ DailyPrice.aspx $>$. Accessed on: May 1, 2018.

Han, C. K.; Sung, K. S.; Yoon, C. S.; Lee, N. H. and Kim, C. S. 1993. Effect of dietary lipids on liver, serum and egg yolk cholesterol content of laying hens. Asian-Australasian Journal of Animal Sciences 6:243-248.

Heier, B. T.; Hogasen, H. R. and Jarp, J. 2002. Factors associated with mortality in Norwegian broiler flocks. Preventive Veterinary Medicine 53:147-158.

Lin, J. Y and Hsu, A. 1998. Study on initial hatching egg weight of Taiwan Country chicken breeders. Journal of the Chinese Society of Animal Science 27:347-354.

Luquetti, B. C.; Gonzales, E.; Bruno, L. D. G.; Furlan, R. L. and Macari, M. 2004. Egg traits and physiological neonatal chick parameters from broiler breeder at different ages. Brazilian Journal of Poultry Science 6:13-17.

Morales-López, R.; Auclair, E.; García, F.; Esteve-Garcia, E. and Brufau, J. 2009. Use of yeast cell walls; $\beta$-1, 3/1, 6-glucans and mannoproteins in broiler chicken diets. Poultry Science 88:601-607.

Mousavi, S. N.; Khalaji, S.; Jirdehi, A. G. and Foroudi, F. 2013. Investigation on the effects of various protein levels with constant ratio of digestible sulfur amino acids and threonine to lysine on performance, egg quality and protein retention in two strains of laying hen. Italian Journal of Animal Science 12:e2. https://doi.org/10.4081/ijas.2013.e2

Muhammad, M.; Muhammad, L. U.; Mani, A. U. and Ambali, A. G. 2009. A survey of chick mortality at hatching in three selected hatcheries in Jos, Central Nigeria. International Journal of Poultry Science 8:656-659.

Musa, H. H.; Chen, G. H.; Cheng, J. H.; Yousif, G. M. 2007. Relation between abdominal fat and serum cholesterol, triglycerides, and lipoprotein concentrations in chicken breeds. Turkish Journal of Veterinary and Animal Sciences 31:375-379.

Naber, E. C. 1983. Nutrient and drug effects on cholesterol metabolism in the laying hen. Federation proceedings 42:2486-2493.

Peebles, E. D.; Burnham, M. R.; Gardner, C. W.; Brake, J.; Bruzual, J. J. and Gerard, P. D. 2001. Effects of incubational humidity and hen age on embryo composition in broiler hatching eggs from young breeders. Poultry Science 80:1299-1304.

Pérez-Bonilla, A.; Novoa, S.; García, J.; Mohiti-Asli, M.; Frikha, M. and Mateos, G. G. 2012. Effects of energy concentration of the diet on productive performance and egg quality of brown 
egg-laying hens differing in initial body weight. Poultry Science 91:3156-3166.

Petek, M. and Dikmen, S. 2006. The effects of prestorage incubation and length of egg storage of broiler breeder eggs on hatchability and subsequent growth performance of progeny. Czech Journal Animal Science 51:73-77.

Petek, M.; Orman, A.; Dikmen, S. and Alpay, F. 2010. Physical chick parameters and effects on growth performance in broiler. Archiv Tierzucht 53:108-115.

Puchajda, H.; Weis, J.; Faruga, A. and Siekiera, J. 1988. The effect of the weight and shape of goose eggs on their hatchability sex and weight of goslings. Acta Zootechnica Universitatis Agriculturae Nitra 44:149-158.

Ramaphala, N. O. and Mbajiorgu, C. A. 2013. Effect of egg weight on hatchability and chick hatch-weight of COBB 500 broiler chickens. Asian Journal of Animal and Veterinary Advances 8:885-892.

Saatci, M.; Kirmizibayrak, T.; Aksoy, A. R and Tülküi, M. 2005. Egg weight, shape index and hatching weight and interrelationships among these traits in native Turkish geese with different coloured feathers. Turkish Journal of Veterinary and Animal Science 29:353-357.

Samanya, M. and Yamauchi, K. 2002. Histological alterations of intestinal villi in chickens fed dried Bacillus subtilis var. natto. Comparative Biochemistry and Physiology Part A: Molecular \& Integrative Physiology 133:95-104.
Shackelford, C.; Long, G.; Wolf, J.; Okerberg, C. and Herbert, R. 2002. Qualitative and quantitative analysis of noneplastic lesions in toxicology studies. Journal of Toxicologic Pathology 30:93-96.

Shanawany, M. M. 1984. Inter-relationship between egg weight, parental age and embryonic development. British Poultry Science 25:449-455.

Shanawany, M. M. 1987. Hatching weight in relation to egg weight in domestic birds. World's Poultry Science 43:107-115.

Spiller, S. V.; Varga, S.; Kovács, M. K. and Kozák, J. 2003. Effect of parents' age and hatching egg weight on liver production of geese. Archiv für Geflügelkunde 67:237-239.

Tona, K.; Bamelis, F.; De Ketelaere, B.; Bruggeman, V.; Moraes, V. M. B.; Buyse, J.; Onagbesan, O. and Decuypere, E. 2003. Effects of egg storage time on spread of hatch, chick quality, and chick juvenile growth. Poultry Science 82:736-741.

Tufft, L. S. and Jensen, L. S. 1991. Effect of age of hen, egg weight, and sex on chick performance and lipid retention. Poultry Science 70:2411-2418

Ulmer-Franco, A. M.; Fasenko, G. M. and O’Dea-Christopher, E. E. 2010. Hatching egg characteristics, chick quality, and broiler performance at 2 breeder flock ages and from 3 egg weights. Poultry Science 89:2735-2742.

Van de Ven, L. J. F.; Van Wagenberg, A. V.; Uitdehaag, K. A.; Groot Koerkamp, P. W. G.; Kemp, B. and Van den Brand, H. 2012. Significance of chick quality score in broiler production. Animal 6:1677-1683. 